\title{
ANÁLISE DISTRIBUTIVA DO ICMS NO ESTADO DO RIO DE JANEIRO - 2002/2003 E 2008/2009(*)(**)
}

\author{
Nelson Leitão Paes ${ }^{a}$
}

RESUMO: Este artigo analisou os aspectos distributivos ligados ao principal tributo sobre o consumo brasileiro, o ICMS, tomando o estado do Rio de Janeiro como foco para a realização do estudo. Tendo por base as informações dos microdados das Pesquisas de Orçamento Familiares de 2002-2003 e 2008-2009, foi possível efetuar o cálculo da carga tributária do ICMS fluminense por grupos de famílias e a análise distributiva do imposto no estado, com o cálculo dos Índices de Kakwani e de Reynolds-Smolensky para os dois períodos. Confirmou-se o fato de que o ICMS do estado do Rio de Janeiro é muito regressivo com peso elevado para as famílias de baixa renda $(10,91 \%$ da renda total) e relativamente reduzido para as de renda mais elevada $(3,66 \%$ da renda total). Não se verificou grande diferença entre a tributação no período 2002/2003 e 2008/2009, mas houve melhora na distribuição de renda e menor concentração do ICMS fluminense. Como consequência, os efeitos sobre a regressividade do imposto foram ambíguos, com melhoria no indicador de Kakwani e piora no de Reynolds-Smolensky.

PALAVRAS-CHAVE: Regressividade; indicadores; ICMS; administração tributária.

CLASSIFICAÇÃO JEL: H20; H22; H31.

\footnotetext{
* Artigo recebido em 06/04/2011 e aprovado em 16/12/2013.

** Versão resumida do trabalho agraciado com o $1^{\circ}$ lugar no tema Finanças Públicas, Política Fiscal e do Gasto Público, Transparência e Responsabilidade Fiscal do II prêmio SEFAZ-SEDEIS em Finanças Públicas e Desenvolvimento Econômico - 2010. O trabalho completo foi publicado como texto de discussão pelas Secretarias de Fazenda e de Desenvolvimento Econômico, Energia, Indústria e Serviços do estado do Rio de Janeiro e pelo Instituto de Estudos do Trabalho e Sociedade. Disponível em: <http://www.iets. org.br/projeto/premio-sefaz-sedeis-ii-em-financas-publicas-e-desenvolvimento-economico-2010>.

a Doutor em Economia pela Universidade de Brasília e professor colaborador do Programa de Pós-Graduação em Economia (PIMES) da Universidade Federal de Pernambuco. Contato: nlpaes@gmail.com.
} 


\title{
DISTRIBUTIONAL ANALYSIS OF ICMS IN THE STATE OF RIO DE JANEIRO - PERIODS 2002-2003 AND 2008-2009
}

\begin{abstract}
This study examined the distributional aspects related to the principal tax on consumption of Brazil, the ICMS, taking the state of Rio de Janeiro as a focus for study. Based on information from individual data on Household Budget Surveys of 2002-2003 and 2008-2009, it was possible to calculate the tax burden of the ICMS by groups of households and to make distributional analysis of tax in the state, by the calculation of Kakwani and Reynolds-Smolensky indices for the two periods. It confirmed the fact that the ICMS on the State of Rio de Janeiro is very regressive with high burden for the low-income families (10.91\% of total income) and relatively low for the highest income (3.66\% of total income). There was no great difference between the burden of the tax in the period 2002/2003 and 2008/2009, but there has been improvement in income distribution and lower concentration of GST fluminense. As a result, the effects on the regressivity of the tax were ambiguous, with improved index Kakwani index and worsening of the Reynolds-Smolensky.
\end{abstract}

KEYWORDS: Regressivity; indexes; ICMS; tax administration. 


\section{INTRODUÇÃO}

A questão da desigualdade tem ocupado cada vez mais a atenção da sociedade brasileira. Acompanha-se com certo interesse, não só acadêmico, mas também na mídia, a evolução de indicadores como o Índice de Gini e o Índice de Desenvolvimento Humano. É um forte sinal de que a tolerância da sociedade brasileira à extrema desigualdade de renda que ainda castiga o nosso país está diminuindo.

Pelo lado da tributação, o caso brasileiro torna-se mais complicado pelo uso extensivo de impostos sobre o consumo, que tem forte propensão a regressividade. A combinação de uma base tributária assentada no consumo, com a falta de transparência, tornam a tributação indireta brasileira um campo propício para a maior desigualdade.

Este trabalho analisou os aspectos distributivos ligados ao principal tributo sobre o consumo brasileiro, o Imposto sobre Circulação de Mercadorias e Serviços (ICMS). Tal imposto, administrado pelos estados, possui características interessantes para estudos distributivos, como sua grande abrangência e sua proximidade a um imposto sobre valor adicionado, o que torna muito mais simples associar a alíquota do tributo a um bem. Escolheu-se o estado do Rio de Janeiro como base para a realização do estudo.

Assim, com informações dos microdados das Pesquisas de Orçamento Familiares de 2002-2003 e 2008-2009, foi possível construir um perfil da cesta de consumo de bens das famílias fluminenses. Em seguida, consultando a legislação estadual, associou-se a cada despesa das famílias uma alíquota do ICMS. Verificou-se que as famílias mais pobres arcam com uma carga cerca de três vezes maior do que as famílias mais ricas, quando tomamos a renda como base de comparação.

$\mathrm{Na}$ análise da progressividade/regressividade foram calculados os Índices de Kakwani ${ }^{1}$ e de Reynolds-Smolensky ${ }^{2}$ para os dois períodos. Confirmou-se a forte regressividade do ICMS fluminense, porém com valores compatíveis ao encontrado pelo estudo de Silveira (2008) que apresenta uma análise específica para o ICMS do estado de São Paulo.

Depois desta breve introdução, o item 2 apresenta uma pequena revisão da literatura sobre a análise distributiva aplicada a tributação indireta, o item 3 detalha a metodologia a ser aplicada e a item 4 traz os resultados para o estado do Rio de Janeiro, Finalmente, o item 5 apresenta as principais conclusões.

\footnotetext{
1 Kakwani (1977) - Ver anexo B.

2 Lambert (2001) - Ver anexo B.
} 


\section{REVISÃO DA LITERATURA: ANÁLISE DISTRIBUTIVA DA TRIBUTAÇÃO INDIRETA}

A análise distributiva da tributação tem ocupado algum espaço na literatura econômica, principalmente no Brasil. Como se sabe o país apresenta altíssimos indicadores de desigualdade e a preocupação se a tributação agrava ou não este quadro, já está transbordando do espaço acadêmico para os meios de comunicação.

Porém, esta atenção aos efeitos da distribuição da tributação é relativamente recente, iniciado no país somente a partir de meados da década de 1990, cujo maior interesse se deu na primeira década do século atual.

Dado o foco do trabalho, voltado ao ICMS, a resenha da literatura que será apresentada, concentra-se na tributação indireta, e mais especificamente sobre este imposto, quando possível. Começamos por textos nacionais.

Vianna et al. (2000) buscaram medir qual seria a carga tributária direta e indireta sobre as unidades familiares nas grandes regiões metropolitanas do Brasil em 1996. O trabalho utilizou os microdados da Pesquisa de Orçamentos Familiares (POF) 19951996 e concluiu que a carga indireta é bastante regressiva para o caso brasileiro, sendo que as famílias com recebimentos de até dois salários-mínimos são as mais penalizadas e as regiões metropolitanas mais pobres (como Fortaleza e Belém) as tributam mais pesadamente do que as mais ricas (São Paulo e Porto Alegre). Na média, as famílias com renda até dois salários-mínimos tinham uma carga de tributação indireta em torno de $26 \%$ e as famílias com rendimentos acima de 30 salários-mínimos uma carga de pouco mais de $7 \%$.

Zockun et al. (2007) em exercício similar calcularam que o peso da tributação indireta é bem superior ao apresentado por Vianna et al. (2008). Segundo os autores, o primeiro decil apresentava uma carga de $26,5 \%$ e $45,8 \%$ do rendimento total, para as POF 1995-1996 e 2002-2003, respectivamente, enquanto o último decil suportava uma carga indireta de $7,3 \%$ e $16,4 \%$. O estudo conclui que foram as famílias mais pobres que suportaram o maior aumento na carga tributária.

Pochman (2008) afirma que são os mais pobres que acabam pagando a maior parte dos tributos no país, mas que ao comparar a carga de tributos por decil de renda entre as Pesquisas de Orçamentos Familiares de 1995-1996 com 2002-2003 verificou que foi a classe média a mais penalizada pelo aumento da carga tributária neste período, seguida pelos decis mais pobres. Para os mais ricos, o incremento na tributação foi menor.

O trabalho de Silveira (2008) na mesma linha calcula a carga tributária por decil de renda e apresenta números de que, em relação à tributação indireta, o primeiro decil, mais pobre, possui alíquota de $29,1 \%$, enquanto que para o último decil, mais rico, esta carga é de apenas 10,1\%. Quanto aos impactos distributivos da tributação, o 
autor estima o valor do índice de Kakwani para o ICMS do estado de São Paulo, tendo encontrado o valor de -0,1426, e também o Índice de Reynolds-Smolensky em -0,0182. Tais resultados indicam forte regressividade e que o ICMS piora a distribuição de renda paulista.

Paes (2004) em trabalho sobre reforma tributária e usando dados da POF 20022003, calcula a carga de tributação indireta suportada pelos mais pobres (até dois salários-mínimos) em 28,07\%, número mais próximo de Silveira (2008) e bastante inferior ao de Zockun et al. (2007). Já em relação aos mais ricos (mais de 20 salários-mínimos), a carga indireta seria de 23,04\%, bem superior aos números de Silveira (2008) e Zockun et al. (2007). Segundo o autor, a alíquota do ICMS seria de 13,25\% para a faixa até dois salários-mínimos e de 9,98\% para a faixa acima de 20 salários mínimos. O autor calculou também os Índices de Kakwani e Reynolds-Smolensky para a tributação indireta total do Brasil, tendo encontrado, -0,0449 e -0,0076, números inferiores ao de Silveira (2008), relativamente ao ICMS paulista, mas com a mesma indicação de regressividade.

Pintos-Payeras e Hoffman (2009) também se dedicam ao estudo da progressividade da tributação, mas usando um enfoque diferente dos trabalhos vistos até aqui: a do sacrifício equitativo. Os autores trabalham com a POF 2002-2003, e encontram para a primeira faixa, renda familiar per capita de até $\mathrm{R} \$ 120,00$, que a tributação indireta representa $24,57 \%$ da renda e o ICMS 13,33\%. Para a última faixa, com renda familiar per capita acima de R \$3.840,00, a carga indireta é de 7,23\% e do ICMS 3,68\%. No texto os autores encontram que a distribuição do sacrifico na tributação ainda não é equitativa, com os mais ricos contribuindo menos do que o calculado.

No plano internacional, são vários os trabalhos analisando a questão distributiva dos tributos. A grande maioria se refere à combinação da tributação direta com as transferências, e são textos aplicados aos países membros da Organização para Cooperação e Desenvolvimento Econômico (OCDE).

Decoster et al. (2009) fazem uma análise distributiva da tributação indireta para cinco países europeus usando um modelo de microssimulação. Os resultados estão dispostos na Tabela 1.

Observa-se um padrão regressivo na tributação dos cinco países. Invariavelmente, as alíquotas incidentes sobre o decil mais pobre são muito maiores do que as do decil mais rico, sempre superior a duas vezes, mas chegando a ser quatro vezes maior no caso da Irlanda. O Índice de Reynolds-Smolensky (R-S na Tabela 1) é negativo o que confirma o fato de que a tributação sobre o consumo piora a distribuição de renda.

Braz e Cunha (2009) analisam o efeito redistributivo do Imposto sobre Valor Adicionado (IVA) em Portugal. O Gráfico 1 ilustra o comportamento regressivo do IVA naquele país, com alíquotas nas camadas mais pobres muito superiores aos das famílias mais ricas. 
Tabela 1 - Dados distributivos para países selecionados

\begin{tabular}{c|c|c|c|c|c}
\hline Decil & Bélgica & Grécia & Hungria & Irlanda & Reino Unido \\
\hline 1 & $23,8 \%$ & $28,6 \%$ & $25,7 \%$ & $24,8 \%$ & $20,6 \%$ \\
\hline 2 & $13,6 \%$ & $22,6 \%$ & $19,3 \%$ & $19,5 \%$ & $14,8 \%$ \\
\hline 3 & $13,3 \%$ & $19,2 \%$ & $17,6 \%$ & $16,6 \%$ & $13,5 \%$ \\
\hline 4 & $12,8 \%$ & $18,8 \%$ & $16,7 \%$ & $15,2 \%$ & $12,5 \%$ \\
\hline 5 & $12,4 \%$ & $17,7 \%$ & $15,8 \%$ & $15,5 \%$ & $11,8 \%$ \\
\hline 6 & $11,8 \%$ & $16,2 \%$ & $15,4 \%$ & $14,2 \%$ & $10,9 \%$ \\
\hline 7 & $11,6 \%$ & $15,8 \%$ & $15,1 \%$ & $13,1 \%$ & $10,8 \%$ \\
\hline 8 & $11,0 \%$ & $14,9 \%$ & $14,7 \%$ & $12,4 \%$ & $10,1 \%$ \\
\hline 9 & $10,8 \%$ & $14,2 \%$ & $14,4 \%$ & $11,0 \%$ & $9,3 \%$ \\
\hline 10 & $9,6 \%$ & $11,9 \%$ & $12,8 \%$ & $7,8 \%$ & $7,5 \%$ \\
\hline Média & $11,8 \%$ & $15,7 \%$ & $15,3 \%$ & $13,2 \%$ & $10,3 \%$ \\
\hline Gini & 0,319 & 0,324 & 0,318 & 0,331 & 0,368 \\
\hline R-S & $-0,011$ & $-0,024$ & $-0,016$ & $-0,015$ & $-0,015$ \\
\hline
\end{tabular}

Fonte: Decoster et al. (2009).

\section{Gráfico 1 - Distribuição do IVA entre as famílias em Portugal}

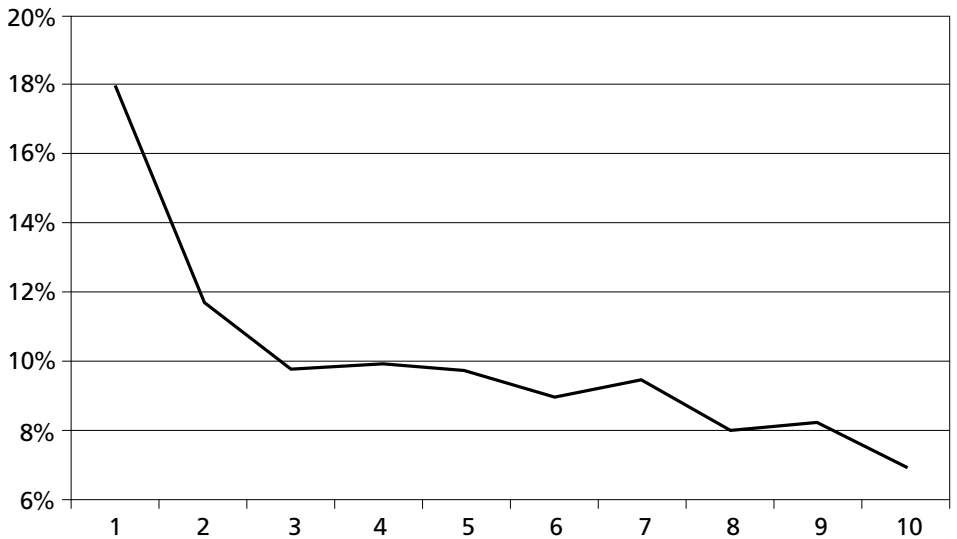

Fonte: Braz e Cunha (2009).

A regressividade é confirmada pelo indicador de Reynolds-Smolensky, calculado pelos autores em $-0,0051$.

Head e Krever (2009) fazem uma análise mais detalhada da tributação da Austrália, entre outros países. Repetindo o padrão visto até o momento, a tributação indireta é muito mais pesada para o primeiro decil, cuja alíquota é de $24,9 \%$, do que para o último decil, de apenas 6,4\%. A carga da tributação indireta sobre os mais pobres é quase quatro vezes superior a dos mais ricos. Esta diferença brutal se reflete nos Índices. O indicador de Kakwani é extremamente elevado com -0,1737, assim como o indicador de Reynolds-Smolensky de -0,0187. 


\section{METODOLOGIA DE TRABALHO}

$\mathrm{Na}$ busca de se estimar o efeito distributivo do ICMS sobre o estado do Rio de Janeiro procedeu-se neste capítulo ao desenvolvimento de metodologia que permita a análise distributiva deste tributo.

As bases de dados utilizadas foram os microdados da Pesquisa de Orçamentos Familiares (POF) 2002-2003 e 2008-2009. A POF traz informações sobre as despesas desagregadas de cada família objeto da pesquisa, bem como apresenta informações sobre condições de vida, alimentação e rendimentos, constituindo-se em valiosa ferramenta para análise da tributação do consumo. A metodologia aqui descrita aplica-se tanto a POF 2002-2003 quanto a POF 2008-2009.

O primeiro passo foi separar as informações das famílias residentes no estado do Rio de Janeiro, foco da nossa análise. Em seguida as famílias foram agrupadas em número de cinquenta em ordem crescente de renda, com cada uma representando aproximadamente $2 \%$ do total de famílias do estado.

No passo seguinte, as despesas de cada família foram agregadas por quadro de despesa da POF. De posse das despesas por quadro e por família, foi possível estabelecer, para cada POF, o quanto percentualmente cada família gasta por item de despesa.

Prosseguindo na metodologia, é preciso associar a cada quadro de despesa uma alíquota do ICMS. Recorreu-se, então, a legislação tributária do estado, de onde se retirou as alíquotas aplicadas. As principais fontes de informação foram a Lei Estadual n 2.657/1996 e o Decreto $\mathrm{n}^{\circ}$ 27.427/2000 (Regulamento do ICMS), com alterações posteriores.

Os anexos A.1 e A.2 mostram as alíquotas do ICMS por quadro de despesa das POF 2002-2003 e 2008-2009, respectivamente.

Aplicando-se a alíquota do ICMS sobre o percentual de despesa de cada quadro, e considerando todas as despesas, obtemos a alíquota do ICMS paga por família. Neste ponto já é possível traçar uma curva, mostrando como a alíquota do ICMS varia com cada faixa de renda, o que já nos permite uma ideia gráfica do efeito distributivo do imposto.

Ao se multiplicar a alíquota do ICMS pela despesa total da família, obtemos o quanto cada uma gasta com este imposto em $\mathrm{R} \$$. Com este valor e com o rendimento por família é possível, então, calcular a renda antes e depois do pagamento do ICMS, e que se constitui nos valores básicos para a análise da progressividade ou regressividade.

De forma a se manter os resultados coerentes com a teoria econômica e evitar um aumento injustificado na regressividade do ICMS fluminense, considerou-se que, para cada família, a despesa total não poderia ser superior a renda total, o que ocorre principalmente nas primeiras faixas de renda.

Para fins de análise foram considerados dois indicadores muito utilizados na avaliação de questões distributivas ligadas a política tributária: o Índice de Kakwani e o Índice de Reynolds-Smolensky. 
Para finalizar a metodologia empregada, podemos comparar as alíquotas e os indicadores obtidos para a POF realizada em 2002-2003 com a pesquisa efetuada em 2008-2009, o que nos permite avaliar como evoluiu o efeito distributivo do ICMS sobre as famílias fluminenses.

\section{RESULTADOS DOS INDICADORES PARA O ESTADO DO RIO DE JANEIRO}

Os resultados que serão apresentados mostram de forma inequívoca o papel regressivo desempenhado pelo ICMS no estado do Rio de Janeiro.

\subsection{CÁLCULO DA ALÍQUOTA DO ICMS POR FAMÍLIA}

Obtidas a distribuição percentual dos gastos de cada família por quadro de despesa e utilizando-se dos resultados dos Anexos A.1 e A.2, é possível apresentar estimativas da alíquota do ICMS, em relação ao total de despesas, por cada família, conforme pode ser visto nos Anexos B.1 e B.2. Os Gráficos 2 e 3 mostram os resultados por faixa de renda crescente.

\section{Gráfico 2 - Alíquotas do ICMS, em relação à despesa total, por faixa de renda (POF 2002-2003)}

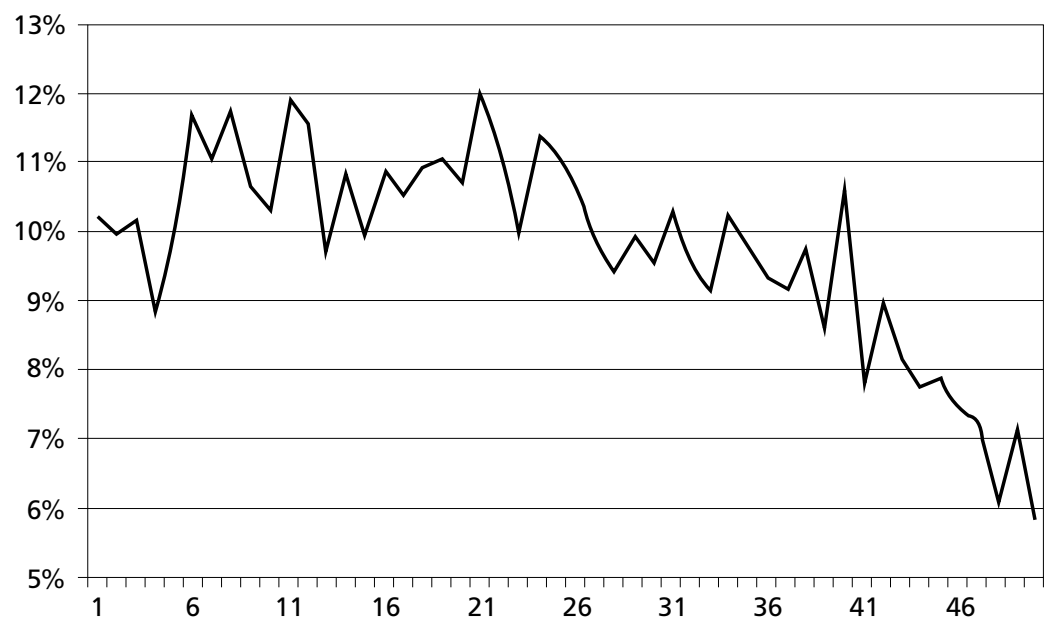


Gráfico 3 - Alíquotas do ICMS, em relação à despesa total, por faixa de renda (POF 2008-2009)

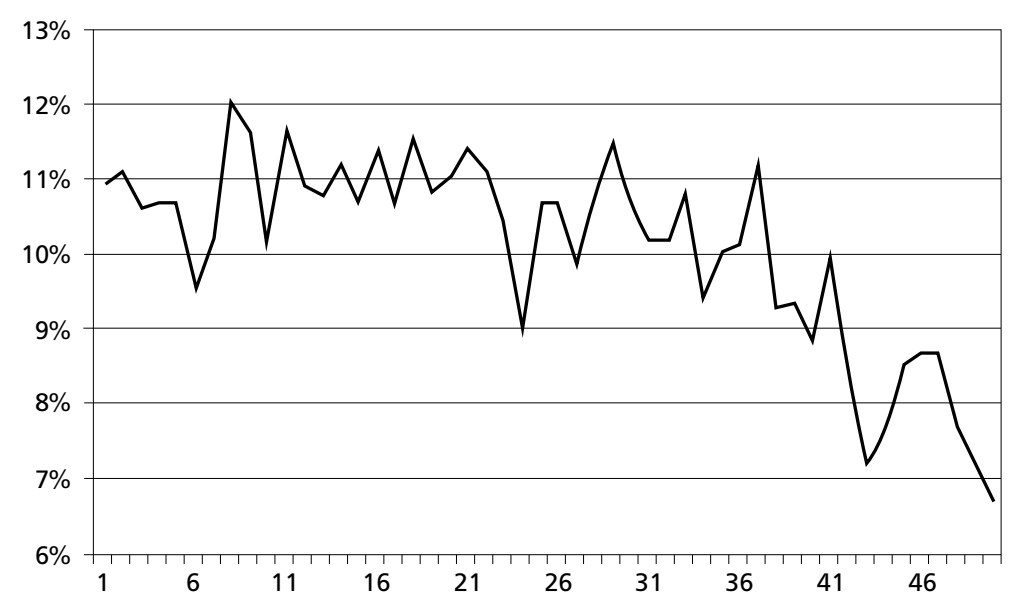

Fonte: Elaboração própria com base nos dados da pesquisa.

Verificou-se que não houve substancial diferença na tributação do ICMS entre 2002-2003 e 2008-2009. As alíquotas aplicadas eram basicamente idênticas, com pequenas diferenças por conta da criação do Fundo Estadual contra a Pobreza ${ }^{3}$.

Assim, em 2002-2003, o gasto com ICMS representava 10,23\% (R\$10,08) da despesa total para a família da primeira faixa, que tem renda média de $\mathrm{R} \$ 98,51$, enquanto que o ICMS representava apenas 5,80\% $(\mathrm{R} \$ 703,19)$ da despesa total para a família da última faixa com rendimento médio de $\mathrm{R} \$ 19.210,00$.

Em 2008-2009 a situação não era diferente. Para a primeira faixa, rendimento médio de $\mathrm{R} \$ 257,42$, a despesa com o ICMS representava $10,91 \%(\mathrm{R} \$ 28,11)$ do gasto total, enquanto para a última faixa, com rendimento médio de $\mathrm{R} \$ 32.321,89$, a despesa com ICMS era de 6,67\% ( $\$$ \$ 1.183,95).

Os gráficos já nos apresentam uma primeira visão da regressividade do ICMS. Mesmo trabalhando com a despesa total, e não com a renda, há uma clara tendência decrescente das alíquotas em relação às faixas de renda. Quanto maior a renda, menor tende a ser a alíquota do ICMS em relação ao gasto total das famílias.

Observando cuidadosamente os dois gráficos, percebemos um padrão entre eles. As alíquotas são mais altas e aproximadamente constantes até o meio da distribuição. Somente na segunda metade, quando as faixas de renda são mais elevadas, é que

3 Lei Estadual n 4.056/2002 regulamentada pelo Decreto Estadual n 32.646/2003. 
ocorre um forte decréscimo das alíquotas. Tal resultado indica certa homogeneidade na cesta de consumo dos bens da metade mais pobre das famílias e alguma diferenciação na cesta de consumo dos mais ricos, que tende mais para bens menos tributados pelo ICMS, em especial serviços, como saúde e educação privada, bem como viagens.

Quando trabalhamos com a renda, e não com a despesa total, a regressividade aparente do ICMS é ainda mais acentuada. Os Gráficos 4 e 5 apresentam os resultados.

\section{Gráfico 4 - Relação entre alíquotas do ICMS e renda (POF 2002-2003)}

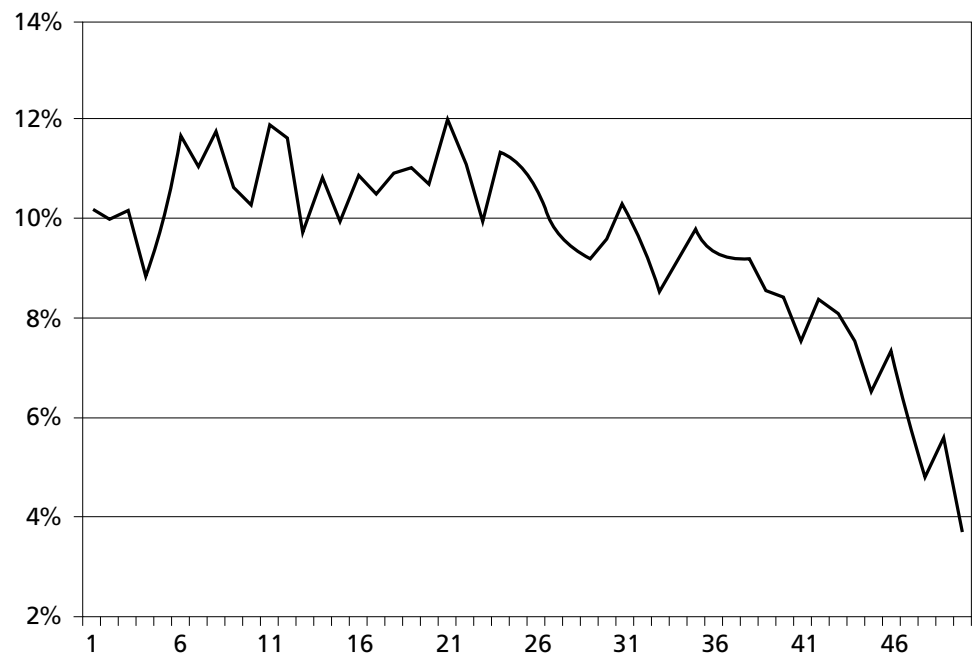

Fonte: Elaboração própria com base nos dados da pesquisa.

Com relação à renda, em 2002-2003, a família da primeira faixa despendia 10,23\% do seu rendimento total com o ICMS, enquanto a família de última faixa gastava apenas 3,66\% da sua renda com o imposto. Para 2008-2009, o quadro é muito similar, com o ICMS custando $10,91 \%$ da renda total para a família da primeira faixa e apenas $3,66 \%$ do total de rendimentos da família mais rica, da última faixa.

É possível comparar o percentual do ICMS gasto pelas famílias em relação a renda, no período entre 2002-2003 e 2008-2009. Esta comparação é interessante para se observar quais as famílias foram beneficiadas/prejudicadas por alterações na tributação ou pela mudança nas preferências dos consumidores, que podem ter migrado para uma cesta de bens mais (ou menos) tributadas, ou ainda por maior crescimento da renda relativo de uma família em relação as demais. O Gráfico 6 ilustra a diferença de alíquotas entre 2008-2009 e 2002-2003. 
Gráfico 5 - Relação entre alíquotas do ICMS e renda (POF 2008-2009)

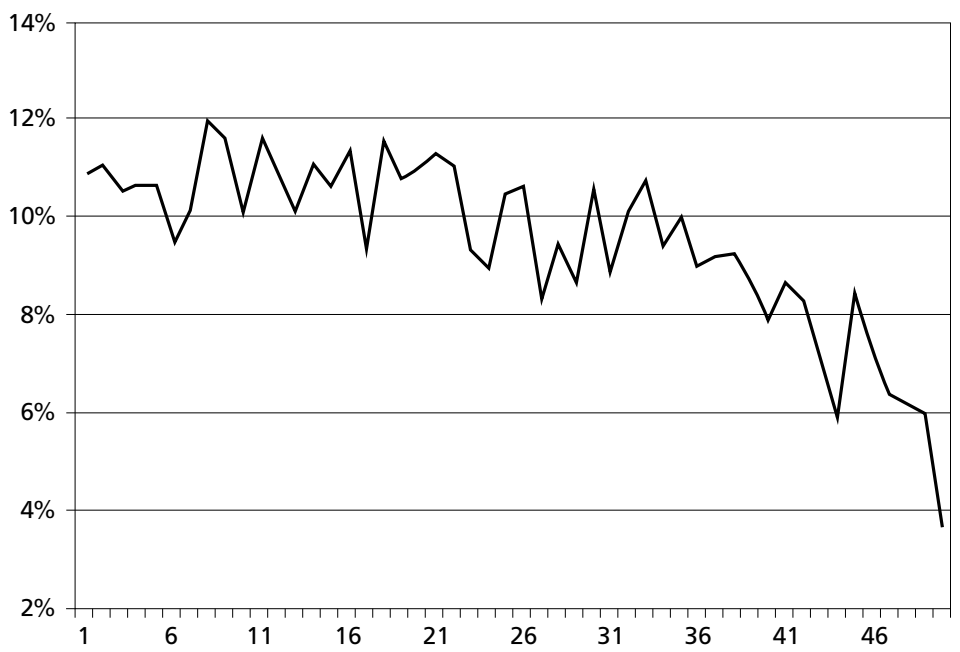

Fonte: Elaboração própria com base nos dados da pesquisa.

Gráfico 6 - Variação das alíquotas do ICMS e renda (2008-2009 e 2002-2003)

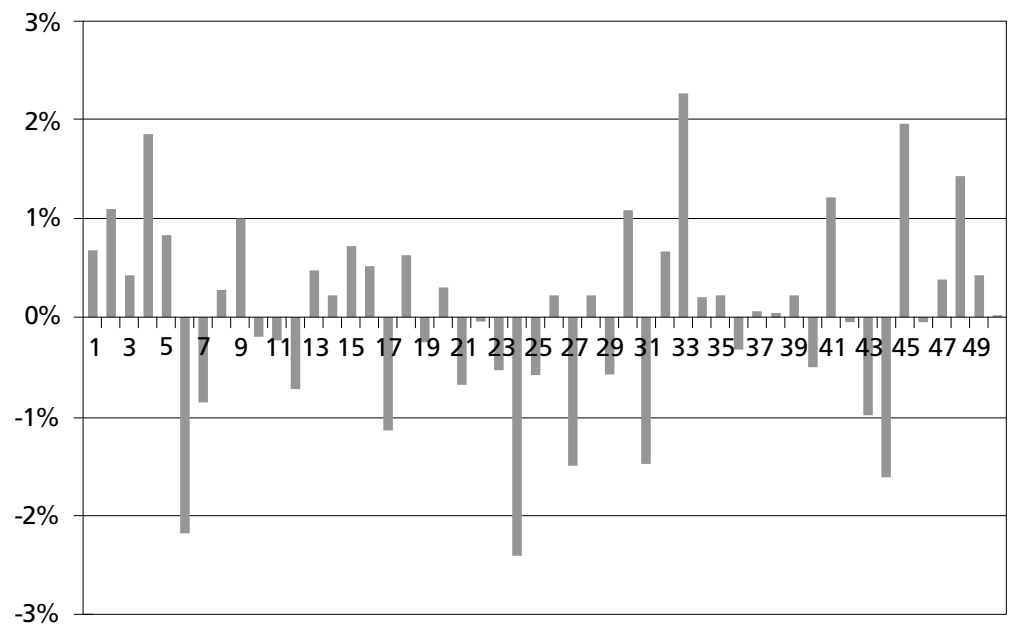

Fonte: Elaboração própria com base nos dados da pesquisa.

Considerando os resultados acima, não se percebe um padrão bem definido nas variações das alíquotas do ICMS, mas é possível deduzir que para as famílias mais pobres houve incremento das alíquotas de até $2 \%$, assim como para as famílias mais 
ricas, com incrementos também nesta faixa. Por outro lado, as famílias de classe média parecem ter sido mais beneficiadas com redução das alíquotas.

Podemos comparar os valores encontrados para o ICMS fluminense com os resultados encontrados pela literatura sobre o tema, apresentados no item 2 deste artigo. A Tabela 2 ilustra a comparação dos resultados com os trabalhos nacionais.

Tabela 2 - Comparação dos resultados - literatura nacional

\begin{tabular}{|c|c|c|c|c|c|}
\hline Artigo & Tributo & Base de dados & $\begin{array}{c}\text { Alíquota grupo } \\
\text { mais pobre }\end{array}$ & \begin{tabular}{|c|}
$\begin{array}{c}\text { Alíquota grupo } \\
\text { mais rico }\end{array}$ \\
\end{tabular} & $\begin{array}{c}\text { Relação } \\
\text { (Pobre/Rico) }\end{array}$ \\
\hline Vianna et al. (2000) & $\begin{array}{l}\text { IPI, ICMS, PIS, } \\
\text { Cofins }\end{array}$ & POF 1995-1996 & $26,00 \%$ & $7,00 \%$ & 3,71 \\
\hline RFB (2002) & ICMS & POF 1995-1996 & $11,74 \%$ & $11,91 \%$ & 1,01 \\
\hline Zockun et al. (2007) & $\begin{array}{l}\text { IPI, PIS, Cofins, } \\
\text { ICMS, ISS }\end{array}$ & POF 1995-1996 & $26,50 \%$ & $7,30 \%$ & 3,63 \\
\hline Zockun et al. (2007) & $\begin{array}{l}\text { IPI, PIS, Cofins, } \\
\text { ICMS, ISS }\end{array}$ & POF 2002-2003 & $45,8 \%$ & $16,4 \%$ & 2,79 \\
\hline Silveira (2008) & $\begin{array}{c}\text { IPI, PIS, ICMS-SP, } \\
\text { Cofins, CIDE }\end{array}$ & POF 2002-2003 & $29,1 \%$ & $10,1 \%$ & 2,88 \\
\hline Paes (2004) & ICMS-SP & POF 2002-2003 & $13,25 \%$ & $9,98 \%$ & 1,33 \\
\hline $\begin{array}{l}\text { Pintos-Payeras } \\
\text { e Hoffman (2009) }\end{array}$ & $\begin{array}{l}\text { ICMS, ISS, PIS, } \\
\text { Cofins e ICMS }\end{array}$ & POF 2002-2003 & $24,57 \%$ & $7,23 \%$ & 3,40 \\
\hline $\begin{array}{l}\text { Pintos-Payeras } \\
\text { e Hoffman (2009) } \\
\end{array}$ & ICMS & POF 2002-2003 & $13,33 \%$ & $3,68 \%$ & 3,62 \\
\hline ICMS Fluminense & ICMS - RJ & POF 2002-2003 & $10,23 \%$ & $3,66 \%$ & 2,80 \\
\hline ICMS Fluminense & ICMS - RJ & POF 2008-2009 & $10,91 \%$ & $3,66 \%$ & 2,98 \\
\hline
\end{tabular}

Fonte: Elaboração própria com base nos dados da pesquisa.

Com relação à literatura nacional, e considerando somente os trabalhos que contemplam apenas o ICMS, a alíquota fluminense sobre o grupo mais pobre encontra-se em patamar um pouco mais baixo do que os outros artigos - RFB (2002), Paes (2004) e Pintos-Payeras e Hoffman (2009) - enquanto que em relação à alíquota sobre o grupo mais rico, o ICMS fluminense está também no grupo de patamar mais baixo.

Já quanto à razão alíquotas do grupo mais pobre em relação ao grupo mais rico, a média fluminense está no grupo intermediário, com valores próximos ao de Zockun et al. (2007) e Silveira (2008).

Portanto, os resultados sugerem que o estado do Rio de Janeiro tributa com o ICMS as famílias num patamar um pouco mais baixo do que a média nacional, tanto para o grupo mais rico quanto para o mais pobre, mas que a razão entre as alíquotas dos dois grupos se mantém na média brasileira.

$\mathrm{Na}$ literatura acadêmica existe discussão sobre qual seria a base mais adequada para medidas de progressividade/regressividade. Para muitos autores, como Creedy (1998) e Poterba (1989), com base na renda vitalícia, poupança nada mais é do que consumo 
futuro, que também será tributado. Mesmo para as famílias mais pobres, onde é possível argumentar que há restrições ao crédito e não há poupança, a despesa também parece ser adequada. Ainda assim, a base renda continua sendo a mais usada na literatura.

Neste trabalho, o uso da base renda ou despesa não altera significativamente os resultados, apenas que a regressividade do ICMS fluminense parece mais acentuado na base renda do que na base despesa.

\subsection{CÁLCULO DOS INDICADORES}

Quanto aos indicadores, ambos confirmam a forte regressividade do ICMS fluminense e seu efeito de aumento da desigualdade. A Tabela 3 apresenta os resultados para os Índices de Gini, Concentração, Kakwani e Reynolds-Smolensky para a POF 20022003 e 2008-2009.

Tabela 3 - Indicadores de desigualdade e progressividade

\begin{tabular}{c|c|c|c|c|c}
\hline & $\begin{array}{c}\text { Índice Gini } \\
\text { Antes ICMS }\end{array}$ & $\begin{array}{c}\text { Índice Gini } \\
\text { Depois ICMS }\end{array}$ & $\begin{array}{c}\text { Índice } \\
\text { Concentração } \\
\text { ICMS }\end{array}$ & $\begin{array}{c}\text { Índice } \\
\text { Kakwani }\end{array}$ & $\begin{array}{c}\text { Índice } \\
\text { Reynolds- } \\
\text { Smolensky }\end{array}$ \\
\hline $\begin{array}{c}\text { POF } \\
2002-2003\end{array}$ & 0,5730 & 0,5833 & 0,4415 & $-0,1315$ & $-0,0103$ \\
\hline $\begin{array}{c}\text { POF } \\
2008-2009\end{array}$ & 0,5565 & 0,5670 & 0,4257 & $-0,1308$ & $-0,0105$ \\
\hline
\end{tabular}

Fonte: Elaboração própria com base nos dados da pesquisa.

O indicador de Gini é bastante acentuado para as famílias fluminenses, mas reflete a extrema desigualdade renda presente no país. O Índice de Concentração do ICMS, bastante inferior ao de Gini, retrata o fato de que a arrecadação do ICMS é muito menos concentrada do que a renda.

Os indicadores de Kakwani e Reynolds-Smolensky confirmam a regressividade do ICMS fluminense já antecipada pelos gráficos anteriores. Assim, a tributação sobre o consumo é regressiva (Kakwani negativo) e piora a distribuição de renda (Reynolds-Smolensky negativo).

A comparação dos indicadores mostra alguma melhoria na distribuição de renda entre 2008-2009 e 2002-2003, fato já apontado por outros trabalhos ${ }^{4}$, o que indica que as famílias dos mais pobres tiveram um aumento de renda relativamente maior do que

\footnotetext{
4 Neri (2010) e Manso et al. (2010).
} 
os mais ricos. A concentração do ICMS também diminuiu no período, o que sugere que famílias mais pobres passaram a pagar relativamente mais tributos do que os mais ricos. Há, portanto, dois efeitos contrários - o da melhoria da distribuição de renda e o da redução da concentração do ICMS, cujos efeitos se refletem nos dois indicadores.

No caso do Índice de Kakwani, o efeito da melhoria da distribuição de renda se sobrepõe ao da redução da concentração do ICMS, acarretando um leve aumento neste indicador de pouco mais de $0,5 \%$. Este aumento indica que houve uma pequena redução da regressividade do ICMS fluminense entre 2008-2009 e 2002-2003.

Por outro lado, quando observamos o Índice de Reynolds-Smolensky, o efeito negativo da diminuição da concentração do ICMS foi maior do que o efeito positivo da redução da desigualdade de renda, levando ao aumento, em termos absolutos, de cerca de $1,8 \%$ do indicador. O incremento revela que o ICMS age de forma mais intensa no aumento da desigualdade em 2008-2009 do que em 2002-2003. Dito de outra forma, o efeito negativo do ICMS sobre a distribuição de renda é maior em 2008-2009 do que em 2002-2003.

É interessante comparar os resultados dos indicadores obtidos para o estado do Rio de Janeiro com os valores encontrados na literatura econômica. A Tabela 4 mostra os números para o Índice de Kakwani.

Tabela 4 - Comparação dos resultados, Índice de Kakwani

\begin{tabular}{c|c|c|c|c}
\hline Artigo & Tributo & Base de dados & País & Índice de Kakwani \\
\hline Silveira (2008) & ICMS - SP & $\begin{array}{c}\text { POF } \\
2002-2003\end{array}$ & Brasil & $-0,1426$ \\
\hline Paes (2004) & ICMS-SP, IPI, PIS, Cofins, CPMF e ISS & $\begin{array}{c}\text { POF } \\
2002-2003\end{array}$ & Brasil & $-0,0449$ \\
\hline ICMS Fluminense & ICMS - RJ & $\begin{array}{c}\text { POF } \\
\mathbf{2 0 0 2 - 2 0 0 3}\end{array}$ & Brasil & $\mathbf{- 0 , 1 3 1 5}$ \\
\hline ICMS Fluminense & ICMS - RJ & $\mathbf{P O F}$ & Brasil & $\mathbf{- 0 , 1 3 0 8}$ \\
\hline Head e Krever (2009) & GST & - & Austrália & $-0,1737$ \\
\hline
\end{tabular}

Fonte: Elaboração própria com base nos dados da pesquisa.

O valor encontrado para o ICMS do Rio de Janeiro é menor do que o encontrado para Silveira (2008), que trabalhou com ICMS de São Paulo, o que sugere que o imposto fluminense seja menos regressivo do que o paulista. Ainda, o ICMS parece ser

\footnotetext{
5 Goods and Services Tax plus Excise Tax.
} 
um tributo mais regressivo do que o conjunto dos tributos indiretos, já que o indicador encontrado por Paes (2004) é bastante inferior aos aqui obtidos e ao de Silveira (2008). Por fim, o indicador australiano é ainda maior do que o encontrado no Brasil.

Quanto ao indicador de Reynolds-Smolensky, temos os seguintes resultados comparativos na Tabela 5.

Tabela 5 - Comparação dos resultados, Índice de Reynolds-Smolensky

\begin{tabular}{c|c|c|c|c}
\hline \multicolumn{1}{c|}{ Artigo } & Tributo & Base de dados & País & R-S \\
\hline Silveira (2008) & ICMS - SP & $\begin{array}{c}\text { POF } \\
2002-2003\end{array}$ & Brasil & $-0,0182$ \\
\hline Paes (2004) & ICMS-SP, IPI, PIS, Cofins, CPMF e ISS & $\begin{array}{c}\text { POF } \\
2002-2003\end{array}$ & Brasil & $-0,0076$ \\
\hline ICMS Fluminense & ICMS - RJ & $\begin{array}{c}\text { POF } \\
\mathbf{2 0 0 2 - 2 0 0 3}\end{array}$ & Brasil & $\mathbf{- 0 , 0 1 0 3}$ \\
\hline ICMS Fluminense & ICMS - RJ & $\mathbf{P O F}$ & Brasil & $-\mathbf{0 , 0 1 0 5}$ \\
\hline Head e Krever (2009) & GST & - & Austrália & $-0,0187$ \\
\hline Braz e Cunha (2009) & VAT & - & Portugal & $-0,0051$ \\
\hline Decoster et al. (2009) & VAT & - & Bélgica & $-0,0110$ \\
\hline Decoster et al. (2009) & VAT & - & Grécia & $-0,0240$ \\
\hline Decoster et al. (2009) & VAT & Hungria & $-0,0160$ \\
\hline Decoster et al. (2009) & VAT & VAT & Reino Unido & $-0,0150$ \\
\hline Decoster et al. (2009) & - & - & $-0,0150$ \\
\hline
\end{tabular}

Fonte: Elaboração própria com base nos dados da pesquisa.

Os resultados da Tabela 5 sugerem que o ICMS fluminense afeta de forma negativa a distribuição de renda, tornando-a mais concentrada, mas que este efeito negativo é bem menor do que no caso do ICMS paulista. Dito de outra forma, o ICMS do Rio de Janeiro piora menos a desigualdade da renda do que o ICMS de São Paulo. Os resultados aqui encontrados e considerando também o trabalho de Silveira (2008), há indicação de que a tributação indireta como um todo, como apontado em Paes (2004), gera menos desigualdade da renda após o imposto do que o ICMS.

Com relação às comparações internacionais apresenta-se um resultado surpreendente. Para a tributação indireta, e também para o ICMS fluminense, o indicador de Reynolds-Smolensky no Brasil aparenta ser inferior ao encontrado na maioria dos países selecionados. Postula-se que o motivo por trás deste resultado é que a desigualdade de renda antes dos impostos indiretos já é muito alta no nosso país e que a distribuição da renda líquida após estes impostos acaba piorando pouco. Para os países 
selecionados, a distribuição de renda antes dos impostos é muito melhor do que no caso brasileiro (ver Tabela 1), e assim os tributos indiretos para este grupo de países afetam mais negativamente a distribuição de renda.

\section{CONCLUSÃO}

Preocupações distributivas com relação à tributação é uma preocupação relativamente recente na literatura econômica brasileira, que passou a ter algum interesse somente a partir da estabilização da economia na segunda metade da década de 1990.

Este trabalho procurou analisar a distribuição da carga do ICMS no estado do Rio de Janeiro com o auxílio de indicadores adequados para a tarefa. Assim, a partir dos microdados das POF 2002-2003 e 2008-2009 traçou-se um perfil das despesas das famílias fluminense, divididas em cinquenta, cada qual representando aproximadamente $2 \%$ da população. Com o uso da legislação tributária do estado calculou-se o a carga de ICMS para cada uma delas, o que possibilitou a análise distributiva. Foram utilizados os Índices de Kakwani e o de Reynolds-Smolensky para aplicar a metodologia.

Os resultados apontam para uma grande regressividade do ICMS fluminense. Para duas pesquisas de orçamento consideradas que a carga do ICMS, em relação à renda, da família mais pobre chega a ser três vezes maior do que a da família mais rica. Quando considerada a carga em relação à despesa, a relação se reduz para o dobro, ainda bastante alto. Os valores, porém, estão compatíveis com as estimativas nacionais e internacionais.

Com relação aos indicadores de progressividade/regressividade, tanto o índice de Kakwani quanto o de Reynolds-Smolensky apresentaram-se com valores extremamente negativos. No caso do primeiro indicador, os números encontrados estão acima dos valores vistos para a literatura internacional, exceção para a Austrália, mas são qualitativamente próximos aos valores existentes na literatura nacional, especialmente a que trata especificamente do ICMS. Quanto ao segundo indicador, surpreendentemente, a tributação indireta brasileira aumenta menos a regressividade do que os valores da literatura internacional considerada.

Os avanços que acompanhamos na redução da desigualdade no país, que permearam toda a primeira década deste século XXI ainda não chegaram a tributação. $O$ trabalho mostrou que não houve mudanças na questão distributiva relacionada ao ICMS no estado do Rio de Janeiro. Os indicadores que já apontavam para forte regressividade em 2002-2003, pouco mudaram em 2008-2009, e o estado convive com uma tributação do seu principal imposto que penaliza os mais pobres com uma carga equi- 
valente a três vezes a dos mais ricos. Talvez já seja o momento de que a maior intolerância da sociedade brasileira com a desigualdade de renda atinja finalmente as Administrações Tributárias do Brasil.

\section{REFERÊNCIAS}

BRAZ, C.; CUNHA, J. The redistributive effects of VAT in Portugal. Economic Bulletin, Banco de Portugal, p. 71-86, Winter, 2009.

DECOSTER, A.; LOUGHREY, J.; O'DONOGHUE, C.; VERWAERFT, D. Incidence and welfare effects of indirect taxes. 2009, Mimeo.

ESTADO DO RIO DE JANEIRO. Decreto Estadual n ${ }^{\circ}$ 26.427/2000.

ESTADO DO RIO DE JANEIRO. Decreto Estadual n $n^{\circ} 32.646 / 2003$.

ESTADO DO RIO DE JANEIRO. Lei Estadual n 2.657/1996.

ESTADO DO RIO DE JANEIRO. Lei Estadual no 4.056/2002.

INSTITUTO BRASILEIRO DE GEOGRAFIA E ESTATÍSTICA (IBGE). Pesquisa de Orçamentos Familiares 2002-2003. Rio de Janeiro: IBGE, 2004.

INSTITUTO BRASILEIRO DE GEOGRAFIA E ESTATÍSTICA (IBGE). Pesquisa de Orçamentos Familiares 2008-2009. Rio de Janeiro: IBGE, 2010.

KAKWANI, N. C. Measurement of tax progressivity: an international comparison. Economic Journal, n. 87, p. 71-80, 1977.

LAMBERT, P. J. The distribution and redistribution of income. 3. ed. Manchester: Manchester University Press, 2001.

MANSO, C.; BARRETO, F.; FRANÇA, J. M. Retornos da Educação e desequilíbrios regionais no Brasil. Revista Brasileira de Economia, v. 64, n. 2, p. 115-133, 2010.

NERI, M. Distribuição de renda: evolução recente. [on-line] Fundação Getúlio Vargas, 2010. Disponível em: <http://www.fgv.br/cps/pesquisas/Politicas_sociais_alunos/2010/BES_DistrRenda_EvoRecente_PME.pdf $>$. Acesso em: 25 out. 2010.

PAES, N. Reforma Tributária: aspectos distributivos e de bem-estar. Tese de Doutorado, Programa de Pós-Graduação em Economia, Departamento de Economia, Universidade de Brasília, Brasília, 2004.

PINTOS-PAYERA, J. A.; HOFFMANN, R. O sacrifico equitativo na tributação brasileira. In: Encontro Nacional de Economia, 37, Foz do Iguaçu, Paraná, 8-11 dez. 2009.

POCHMAN, M. Tributação que aprofunda a desigualdade. Carta Social e do Trabalho, UNICAMP, n. 8, jan./ago. 2008.

SECRETARIA DA RECEITA FEDERAL DO BRASIL (RFB). A progressividade no consumo: tributação cumulativa e sobre o valor agregado. Estudo Tributário, Brasília, n. 4, 2002.

SILVEIRA, F. Tributação, previdência e assistência sociais: impactos distributivos. Tese de Doutorado em Economia, Instituto de Economia, Universidade Estadual de Campinas, São Paulo, 2008. 
VIANNA, S.; MAGALHÃES, L.; SILVEIRA, F.; TOMICH, F. Carga tributária direta e indireta sobre as unidades familiares no Brasil: avaliação de sua incidência nas grandes regiões urbanas em 1996. Texto para Discussão, IPEA, Brasília, n. 757, 2000.

ZOCKUN, M.; ZYLBERSTAJN, H.; SILBER, S.; RIZZIERI, J.; PORTELA, A.; PELLIN, E.; AFONSO, L. Simplificando o Brasil: propostas de reforma na relação econômica do governo com o setor privado. Texto para Discussão, FIPE, São Paulo, n. 3, 2007. 


\section{ANEXOS}

ANEXO A.1 - QUADRO DE DESPESAS DAS FAMÍLIAS E ALÍQUOTAS ICMS - POF 2002-2003

\begin{tabular}{|c|c|c|c|c|c|}
\hline \multicolumn{2}{|r|}{ QUADRO DE DESPESAS } & \multirow{2}{*}{$\begin{array}{c}\text { ICMS } \\
\left(^{*}\right)\end{array}$} & \multicolumn{2}{|r|}{ QUADRO DE DESPESAS } & \multirow{2}{*}{$\frac{\text { ICMS }}{18 \%}$} \\
\hline 7 & $\begin{array}{l}\text { Despesas com Serviços e Taxas do } \\
\text { Domicílio }\end{array}$ & & 36 & Despesas com Roupas de Criança & \\
\hline & Energia elétrica & $(* *)$ & 37 & Despesas com Artigos de Armarinho & $18 \%$ \\
\hline & Telefone fixo & $25 \%$ & 38 & Despesas com Bolsas, Calçados e Cintos & $18 \%$ \\
\hline & Telefone Celular & $25 \%$ & 39 & $\begin{array}{l}\text { Despesas com Artigos de Banheiro, Copa } \\
\text { e Cozinha }\end{array}$ & $18 \%$ \\
\hline & Gás doméstico & $18 \%$ & 40 & Outras despesas & $18 \%$ \\
\hline & Água e esgoto & $0 \%$ & 41 & Despesas com Viagens & $0 \%$ \\
\hline & Outros & $10 \%$ & 42 & Despesas com Assistência à Saúde & $0 \%$ \\
\hline 8 & Manutenção e Reparos com o Domicílio & $9 \%$ & 43 & $\begin{array}{l}\text { Despesas com Acessórios e Manutenção } \\
\text { de Veículos }\end{array}$ & $18 \%$ \\
\hline 9 & $\begin{array}{l}\text { Conserto e Manutenção de Utensílios } \\
\text { Doméstico }\end{array}$ & $9 \%$ & 44 & $\begin{array}{l}\text { Despesas com Serviços Bancários e } \\
\text { Profissionais }\end{array}$ & $0 \%$ \\
\hline 10 & Despesas com Habitação & $0 \%$ & 45 & $\begin{array}{l}\text { Despesas com Cerimônias Familiares e } \\
\text { Religiosas }\end{array}$ & $0 \%$ \\
\hline 11 & Despesas com Construção e Reformas & $9 \%$ & 46 & $\begin{array}{l}\text { Despesas com Joias, Relógios e Aparelhos } \\
\text { Celulares }\end{array}$ & $18 \%$ \\
\hline 12 & Outros Serviços e Taxas de Habitação & $0 \%$ & 47 & Despesas com Outros Imóveis & $0 \%$ \\
\hline 13 & Aluguel de Aparelhos de Uso Doméstico & $0 \%$ & 48 & $\begin{array}{l}\text { Despesas com Contribuições e } \\
\text { Transferência Financeiras }\end{array}$ & $0 \%$ \\
\hline 15 & Aquisição de Aparelhos e Máquinas & $18 \%$ & 49 & Despesas com Educação & $0 \%$ \\
\hline 16 & Aquisição de Instrumentos e Utilidades & $18 \%$ & 50 & $\begin{array}{l}\text { Despesas com Documentação, Seguro } \\
\text { com Veículos }\end{array}$ & $0 \%$ \\
\hline 17 & Aquisição de Móveis & $12 \%$ & 51 & Despesas com Aquisição de Veículos & $12 \%$ \\
\hline 18 & Artigos de Decoração e Forração & $18 \%$ & 63 & $\begin{array}{l}\text { Cereais, leguminosas e hortaliças } \\
\text { tuberosas }\end{array}$ & $12 \%$ \\
\hline 19 & Despesas com Serviços Domésticos & $0 \%$ & 64 & $\begin{array}{l}\text { Farinhas, féculas, massas, cocos, castanhas } \\
\text { e nozes }\end{array}$ & $18 \%$ \\
\hline 22 & Despesas com Comunicações & $25 \%$ & 65 & Hortaliças folhosas, frutosas e outras & $18 \%$ \\
\hline 23 & Despesas com Transportes & $0 \%$ & 66 & Frutas & $8 \%$ \\
\hline 24 & Despesas com Alimentação Fora & $12 \%$ & 67 & Açúcares e produtos de confeitaria & $18 \%$ \\
\hline 25 & Despesas com Fumo & $25 \%$ & 68 & Sais e condimentos & $12 \%$ \\
\hline 26 & Despesas com Jogos e Apostas & $0 \%$ & 69 & Carnes e vísceras & $12 \%$ \\
\hline 27 & Despesas com Leitura & $0 \%$ & $70-89$ & Pescados & $8 \%$ \\
\hline 28 & $\begin{array}{l}\text { Despesas com Diversões, Esportes e } \\
\text { Apostas }\end{array}$ & $0 \%$ & 90 & Enlatados e conservas & $18 \%$ \\
\hline 29 & Despesas com Produtos Farmacêuticos & $18 \%$ & 91 & Aves, ovos e laticínios & $12 \%$ \\
\hline 30 & Despesas com Artigos de Higiene e Beleza & $18 \%$ & 92 & Panificados e carnes industrializadas & $12 \%$ \\
\hline 31 & Despesas com Serviços Pessoais & $0 \%$ & 93 & Bebidas não alcoólicas e infusões & $20 \%$ \\
\hline 32 & Despesas com Artigos de Papelaria & $0 \%$ & 94 & $\begin{array}{l}\text { Óleos, gorduras e alimentos preparados } \\
\text { ou semipreparados }\end{array}$ & $18 \%$ \\
\hline 33 & Despesas com Brinquedos e recreação & $18 \%$ & 95 & Produtos de limpeza doméstica e outros & $18 \%$ \\
\hline 34 & Despesas com Roupas de Homem & $18 \%$ & 96 & $\begin{array}{l}\text { Produtos de higiene corporal e bebidas } \\
\text { alcoólicas }\end{array}$ & $20 \%$ \\
\hline 35 & Despesas com Roupas de Mulher & $18 \%$ & 99 & Agregados & $18 \%$ \\
\hline
\end{tabular}

(*) A alíquota de cada família será variável dependendo da alíquota da energia elétrica.

(**) A alíquota da energia depende do consumo - Até $50 \mathrm{Kw} / \mathrm{h}$ - 0\% (Até $2 \mathrm{SM}$ ); De 50 a $300 \mathrm{Kw} / \mathrm{h}$ - 18\% (De 2 a 15 SM);

Mais de $300 \mathrm{Kw} / \mathrm{h}-25 \%$ (Mais de $15 \mathrm{SM}$ ); 
Anexo A.2 - Quadro de Despesas das Famílias e Alíquotas ICMS - POF 2008-2009

\begin{tabular}{|c|c|c|c|c|c|}
\hline \multicolumn{2}{|r|}{ QUADRO DE DESPESAS } & \multirow{2}{*}{$\frac{\text { ICMS }}{\left({ }^{*}\right)}$} & \multicolumn{2}{|r|}{ QUADRO DE DESPESAS } & \multirow{2}{*}{$\begin{array}{c}\text { ICMS } \\
18 \%\end{array}$} \\
\hline 6 & Serviços e taxas do domicílio principal & & 39 & $\begin{array}{l}\text { Aquisição utensílios e artigos de banheiro } \\
\text { e cozinha }\end{array}$ & \\
\hline & Energia elétrica & $(* *)$ & 40 & Outras aquisições & $18 \%$ \\
\hline & Telefone fixo & $25 \%$ & 41 & Viagens & $0 \%$ \\
\hline & Telefone celular & $25 \%$ & 42 & Serviços de assistência à saúde & $0 \%$ \\
\hline & Pacote de telefone, TV e Internet & $10 \%$ & 43 & Acessórios e manutenção de veículos & $18 \%$ \\
\hline & Gás doméstico & $18 \%$ & 44 & $\begin{array}{l}\text { Serviços bancários, cartório, advogado e } \\
\text { similares }\end{array}$ & $0 \%$ \\
\hline & Água e esgoto & $0 \%$ & 45 & $\begin{array}{l}\text { Cerimônias familiares, religiosas e outras } \\
\text { festas }\end{array}$ & $0 \%$ \\
\hline & Outros & $10 \%$ & 46 & $\begin{array}{l}\text { Aquisição de jóias, relógios e aparelhos } \\
\text { celulares }\end{array}$ & $18 \%$ \\
\hline 7 & $\begin{array}{l}\text { Aquisição de combustíveis domésticos e } \\
\text { outros }\end{array}$ & $18 \%$ & 47 & Outros Imóveis & $0 \%$ \\
\hline 8 & $\begin{array}{l}\text { Conservação, manutenção e pequenos } \\
\text { reparos }\end{array}$ & $9 \%$ & 48 & $\begin{array}{l}\text { Contribuições, transferências e encargos } \\
\text { financeiros }\end{array}$ & $0 \%$ \\
\hline 9 & $\begin{array}{l}\text { Consertos e manutenção de móveis, } \\
\text { aparelhos, máquinas e utensílios de uso } \\
\text { doméstico }\end{array}$ & $9 \%$ & 49 & $\begin{array}{l}\text { Cursos, livros didáticos, revistas técnicas } \\
\text { e outros itens referentes à educação }\end{array}$ & $0 \%$ \\
\hline 10 & $\begin{array}{l}\text { Aluguel, impostos e outras taxas do } \\
\text { domicílio principal }\end{array}$ & $0 \%$ & 50 & Veículos: documentação, seguro e outros & $0 \%$ \\
\hline 11 & $\begin{array}{l}\text { Construção e reforma de habitação e } \\
\text { jazigo }\end{array}$ & $9 \%$ & 51 & Aquisição de veículos & $12 \%$ \\
\hline 12 & Outros itens do domicílio principal & $0 \%$ & 63 & Cereais e leguminosas & $12 \%$ \\
\hline 13 & $\begin{array}{l}\text { Aluguel de aparelhos e utilidades de uso } \\
\text { doméstico }\end{array}$ & $0 \%$ & 64 & Hortaliças tuberosas & $18 \%$ \\
\hline 14 & Inventário de bens duráveis & $0 \%$ & 65 & Farinhas, féculas e massas & $18 \%$ \\
\hline 15 & $\begin{array}{l}\text { Aquisição de aparelhos, máquinas e } \\
\text { outras utilidades de uso doméstico }\end{array}$ & $18 \%$ & 66 & Cocos, castanhas e nozes & $18 \%$ \\
\hline 16 & $\begin{array}{l}\text { Aquisição de ferramentas, animais } \\
\text { domésticos, equipamentos musicais e de } \\
\text { acampamento }\end{array}$ & $18 \%$ & 67 & Hortaliças folhosas, frutosas e outras & $18 \%$ \\
\hline 17 & Aquisição de móveis & $13 \%$ & 68 & Frutas & $9 \%$ \\
\hline 18 & $\begin{array}{l}\text { Aquisição de artigos de decoração e } \\
\text { forração }\end{array}$ & $18 \%$ & 69 & Açúcares e produtos de confeitaria & $18 \%$ \\
\hline 19 & Serviços domésticos & $0 \%$ & 70 & Sais e condimentos & $12 \%$ \\
\hline 20 & Aluguel Imputado & $0 \%$ & 71 & Carnes e vísceras & $12 \%$ \\
\hline 22 & Comunicações & $25 \%$ & 72 & Pescados marinhos & $9 \%$ \\
\hline 23 & Transportes coletivos e próprios & $0 \%$ & 74 & Pescados de água doce & $9 \%$ \\
\hline 24 & Alimentação fora de casa & $12 \%$ & 76 & Pescados não especificados & $9 \%$ \\
\hline 25 & Aquisição de artigos de fumo & $26 \%$ & 77 & Enlatados e conservas & $18 \%$ \\
\hline 26 & Jogos e Apostas & $0 \%$ & 78 & Aves e ovos & $12 \%$ \\
\hline 27 & $\begin{array}{l}\text { Aquisição de jornais, revistas e } \\
\text { passatempos impressos }\end{array}$ & $0 \%$ & 79 & Laticínios & $18 \%$ \\
\hline 28 & $\begin{array}{l}\text { Diversões, eventos esportivos e culturais } \\
\text { e celulares }\end{array}$ & $19 \%$ & 80 & Panificados & $12 \%$ \\
\hline 29 & Aquisição de produtos farmacêuticos & $18 \%$ & 81 & Carnes industrializadas & $12 \%$ \\
\hline 30 & $\begin{array}{l}\text { Aquisição de artigos de higiene pessoal e } \\
\text { maquiagem }\end{array}$ & $18 \%$ & 82 & Bebidas não alcoólicas e infusões & $20 \%$ \\
\hline 31 & Serviços de cuidados pessoais e outros & $0 \%$ & 83 & Bebidas alcoólicas & $20 \%$ \\
\hline 32 & $\begin{array}{l}\text { Aquisição de artigos de papelaria, livros } \\
\text { não didáticos e assinatura de periódicos }\end{array}$ & $0 \%$ & 84 & Óleos e gorduras & $18 \%$ \\
\hline 33 & $\begin{array}{l}\text { Aquisição de brinquedos e material de } \\
\text { recreação }\end{array}$ & $18 \%$ & 85 & $\begin{array}{l}\text { Alimentos preparados ou semi } \\
\text { preparados }\end{array}$ & $18 \%$ \\
\hline
\end{tabular}




\begin{tabular}{c|l|c|c|l|l}
\hline 34 & Aquisição e aluguel de roupas de homem & $18 \%$ & 86 & Produtos de limpeza doméstica e outros & $18 \%$ \\
\hline 35 & Aquisição e aluguel de roupas de mulher & $18 \%$ & 87 & $\begin{array}{l}\text { Alimentos e produtos de higiene para } \\
\text { animais }\end{array}$ & $18 \%$ \\
\hline 36 & $\begin{array}{l}\text { Aquisição e aluguel de roupas de criança } \\
\text { até 14 anos }\end{array}$ & $18 \%$ & 88 & Flores naturais & $0 \%$ \\
\hline 37 & $\begin{array}{l}\text { Aquisição de artigos de armarinho, } \\
\text { tecidos e roupas }\end{array}$ & $18 \%$ & 89 & Produtos de higiene corporal & $18 \%$ \\
\hline 38 & $\begin{array}{l}\text { Aquisição e aluguel de bolsas, calçados e } \\
\text { cintos }\end{array}$ & $18 \%$ & 90 & Agregados & $18 \%$ \\
\hline
\end{tabular}

(*) A alíquota de cada família será variável dependendo da alíquota da energia elétrica.

$\left.{ }^{* *}\right)$ A alíquota da energia depende do consumo - Até $50 \mathrm{Kw} / \mathrm{h}$ - 0\% (Até $2 \mathrm{SM}$ ); De 50 a $300 \mathrm{Kw} / \mathrm{h}$ - 18\% (De 2 a 15 SM); Mais de $300 \mathrm{Kw} / \mathrm{h}-25 \%$ (Mais de $15 \mathrm{SM}$ );

Anexo B.1 - Distribuição da Alíquota do ICMS por família - POF 2002-2003

\begin{tabular}{|c|c|c|c|c|c|c|c|c|c|}
\hline \multicolumn{4}{|c|}{ Faixas de Renda } & \multirow{2}{*}{$\begin{array}{l}\text { ICMS } \\
8,58 \%\end{array}$} & \multicolumn{4}{|c|}{ Faixas de Renda } & \multirow{2}{*}{$\begin{array}{l}\text { ICMS } \\
8,83 \%\end{array}$} \\
\hline & Até & & 163,00 & & $\mathrm{De}$ & $1.156,00$ & A & $1.202,00$ & \\
\hline De & 163,00 & A & 234,00 & $8,28 \%$ & $\mathrm{De}$ & $1.202,00$ & $\mathrm{~A}$ & $1.268,00$ & $8,16 \%$ \\
\hline $\mathrm{De}$ & 234,00 & A & 289,00 & $8,48 \%$ & $\mathrm{De}$ & $1.268,00$ & A & $1.338,00$ & $7,85 \%$ \\
\hline De & 289,00 & A & 339,00 & $7,32 \%$ & De & $1.338,00$ & A & $1.407,00$ & $8,24 \%$ \\
\hline $\mathrm{De}$ & 339,00 & A & 377,00 & $8,18 \%$ & $\mathrm{De}$ & $1.407,00$ & A & $1.469,00$ & $7,93 \%$ \\
\hline De & 377,00 & A & 425,00 & $9,69 \%$ & De & $1.469,00$ & $\mathrm{~A}$ & $1.550,00$ & $8,49 \%$ \\
\hline De & 425,00 & A & 457,00 & $9,18 \%$ & $\mathrm{De}$ & $1.550,00$ & A & $1.637,00$ & $7,88 \%$ \\
\hline $\mathrm{De}$ & 457,00 & A & 485,00 & $9,74 \%$ & $\mathrm{De}$ & $1.637,00$ & A & $1.730,00$ & $7,58 \%$ \\
\hline De & 485,00 & A & 518,00 & $8,83 \%$ & $\mathrm{De}$ & $1.730,00$ & A & $1.824,00$ & $8,47 \%$ \\
\hline De & 518,00 & A & 540,00 & $8,54 \%$ & $\mathrm{De}$ & $1.824,00$ & A & $1.994,00$ & $8,11 \%$ \\
\hline De & 540,00 & A & 574,00 & $9,84 \%$ & $\mathrm{De}$ & $1.994,00$ & A & $2.224,00$ & $7,74 \%$ \\
\hline De & 574,00 & A & 624,00 & $9,54 \%$ & $\mathrm{De}$ & $2.224,00$ & A & $2.412,00$ & $7,62 \%$ \\
\hline De & 624,00 & A & 648,00 & $7,98 \%$ & $\mathrm{De}$ & $2.412,00$ & A & $2.601,00$ & $8,14 \%$ \\
\hline De & 648,00 & A & 678,00 & $9,10 \%$ & $\mathrm{De}$ & $2.601,00$ & A & $2.859,00$ & $7,21 \%$ \\
\hline De & 678,00 & A & 714,00 & $8,19 \%$ & $\mathrm{De}$ & $2.859,00$ & A & $3.147,00$ & $8,76 \%$ \\
\hline De & 714,00 & A & 747,00 & $8,93 \%$ & De & $3.147,00$ & A & $3.397,00$ & $6,41 \%$ \\
\hline De & 747,00 & A & 788,00 & $8,68 \%$ & De & $3.397,00$ & A & $3.713,00$ & $7,50 \%$ \\
\hline De & 788,00 & A & 829,00 & $9,10 \%$ & $\mathrm{De}$ & $3.713,00$ & A & $4.432,00$ & $6,72 \%$ \\
\hline De & 829,00 & A & 871,00 & $9,13 \%$ & $\mathrm{De}$ & $4.432,00$ & A & $5.059,00$ & $6,39 \%$ \\
\hline De & 871,00 & A & 911,00 & $8,90 \%$ & $\mathrm{De}$ & $5.059,00$ & A & $5.647,00$ & $6,48 \%$ \\
\hline De & 911,00 & A & 968,00 & $9,95 \%$ & De & $5.647,00$ & A & $6.496,00$ & $6,17 \%$ \\
\hline De & 968,00 & A & $1.025,00$ & $9,22 \%$ & De & $6.496,00$ & A & $7.617,00$ & $6,04 \%$ \\
\hline De & $1.025,00$ & A & $1.066,00$ & $8,19 \%$ & De & $7.617,00$ & A & $9.632,00$ & $5,04 \%$ \\
\hline De & $1.066,00$ & A & $1.117,00$ & $9,42 \%$ & De & $9.632,00$ & $\mathrm{~A}$ & $13.555,00$ & $5,93 \%$ \\
\hline De & $1.117,00$ & A & $1.156,00$ & $9,11 \%$ & & Acima de & & $13.555,00$ & $4,84 \%$ \\
\hline
\end{tabular}


Anexo B.2 - Distribuição da Alíquota do ICMS por família - POF 2008-2009

\begin{tabular}{|c|c|c|c|c|c|c|c|c|c|}
\hline \multicolumn{4}{|c|}{ Faixas de Renda } & ICMS & \multicolumn{4}{|c|}{ Faixas de Renda } & ICMS \\
\hline \multicolumn{3}{|c|}{ Até } & 369,00 & $9,01 \%$ & $\mathrm{De}$ & $1.856,00$ & A & $1.947,00$ & $8,92 \%$ \\
\hline De & 369,00 & A & 516,00 & $9,29 \%$ & $\mathrm{De}$ & $1.947,00$ & A & $2.020,00$ & $8,16 \%$ \\
\hline De & 516,00 & A & 583,00 & $8,81 \%$ & $\mathrm{De}$ & $2.020,00$ & A & $2.126,00$ & $8,92 \%$ \\
\hline De & 583,00 & A & 635,00 & $8,83 \%$ & $\mathrm{De}$ & $2.126,00$ & A & $2.194,00$ & $9,52 \%$ \\
\hline De & 635,00 & A & 704,00 & $8,85 \%$ & De & $2.194,00$ & A & $2.316,00$ & $8,87 \%$ \\
\hline De & 704,00 & A & 737,00 & $7,92 \%$ & $\mathrm{De}$ & $2.316,00$ & A & $2.445,00$ & $8,49 \%$ \\
\hline De & 737,00 & A & 808,00 & $8,55 \%$ & $\mathrm{De}$ & $2.445,00$ & A & $2.585,00$ & $8,53 \%$ \\
\hline De & 808,00 & A & 869,00 & $9,94 \%$ & $\mathrm{De}$ & $2.585,00$ & A & $2.701,00$ & $8,96 \%$ \\
\hline De & 869,00 & A & 909,00 & $9,59 \%$ & $\mathrm{De}$ & $2.701,00$ & A & $2.875,00$ & $7,80 \%$ \\
\hline De & 909,00 & A & 951,00 & $8,41 \%$ & $\mathrm{De}$ & $2.875,00$ & A & $3.031,00$ & $8,30 \%$ \\
\hline De & 951,00 & A & 998,00 & $9,67 \%$ & $\mathrm{De}$ & $3.031,00$ & A & $3.216,00$ & $8,36 \%$ \\
\hline De & 998,00 & A & $1.042,00$ & $9,00 \%$ & $\mathrm{De}$ & $3.216,00$ & A & $3.422,00$ & $9,27 \%$ \\
\hline De & $1.042,00$ & A & $1.101,00$ & $8,94 \%$ & $\mathrm{De}$ & $3.422,00$ & A & $3.581,00$ & $7,79 \%$ \\
\hline De & $1.101,00$ & A & $1.146,00$ & $9,25 \%$ & $\mathrm{De}$ & $3.581,00$ & A & $3.853,00$ & $7,80 \%$ \\
\hline De & $1.146,00$ & A & $1.194,00$ & $8,81 \%$ & $\mathrm{De}$ & $3.853,00$ & A & $4.219,00$ & $7,38 \%$ \\
\hline De & $1.194,00$ & A & $1.253,00$ & $9,40 \%$ & $\mathrm{De}$ & $4.219,00$ & A & $4.616,00$ & $8,32 \%$ \\
\hline De & $1.253,00$ & A & $1.304,00$ & $8,80 \%$ & $\mathrm{De}$ & $4.616,00$ & A & $4.972,00$ & $6,98 \%$ \\
\hline De & $1.304,00$ & A & $1.364,00$ & $9,61 \%$ & $\mathrm{De}$ & $4.972,00$ & A & $5.509,00$ & $5,95 \%$ \\
\hline De & $1.364,00$ & A & $1.403,00$ & $8,95 \%$ & $\mathrm{De}$ & $5.509,00$ & A & $6.493,00$ & $6,31 \%$ \\
\hline De & $1.403,00$ & A & $1.438,00$ & $9,13 \%$ & $\mathrm{De}$ & $6.493,00$ & A & $7.236,00$ & $7,11 \%$ \\
\hline $\mathrm{De}$ & $1.438,00$ & A & $1.512,00$ & $9,48 \%$ & $\mathrm{De}$ & $7.236,00$ & A & $9.310,00$ & $7,18 \%$ \\
\hline De & $1.512,00$ & A & $1.615,00$ & $9,13 \%$ & $\mathrm{De}$ & $9.310,00$ & A & $11.653,00$ & $7,20 \%$ \\
\hline De & $1.615,00$ & A & $1.714,00$ & $8,60 \%$ & $\mathrm{De}$ & $11.653,00$ & A & $14.282,00$ & $6,32 \%$ \\
\hline De & $1.714,00$ & A & $1.783,00$ & $7,43 \%$ & $\mathrm{De}$ & $14.282,00$ & A & $21.453,00$ & $6,03 \%$ \\
\hline De & $1.783,00$ & A & $1.856,00$ & $8,83 \%$ & & Acima de & & $21.453,00$ & $5,61 \%$ \\
\hline
\end{tabular}

